\title{
VI
}

\section{CORPOS, MÁQUINAS E AFETOS: AS EXPERIÊNCIAS HOMOSSEXUAIS NA CONTEMPORANEIDADE*}

Felipe Pancheri Colpani

\section{Introdução}

A pesquisa intitulada "Corpos, Máquinas e Afetos: as experiências homossexuais na contemporaneidade" buscou compreender como os territórios virtuais do ciberespaço têm-se constituído como novos vetores de subjetivação para a produção de experiências homossexuais. Entendo a subjetivação como o processo de constituição do ser e os territórios virtuais como novos meios para esse processo constitutivo (COLPANI, 2015).

No encontro com as máquinas virtuais, nos deparamos com um conjunto de territórios virtuais desterritorializados para a navegação e que passam a se integrar aos territórios sociais preexistentes, aumentando, assim, as possibilidades de interação e formação de redes. As vivências têm-se tornado cada vez mais produzidas a partir de um intercâmbio entre múltiplos territórios híbridos. As máquinas virtuais têm oferecido uma gama de sistemas de simulação que parecem se convergir em um novo tipo cotidiano [cibercotidiano]. As distâncias geográficas são aniquiladas pelas redes móveis que interconectam os corpos a um único ciberorganismo mutante - um ambiente geográfico integrado.

As novas próteses eletrônicas de subjetivação se apresentam como territórios movediços de produção existencial. Introduzem no espaço, aldeias moleculares [sítios eletrônicos e redes sociais] de simulação virtual: de agrupamento, de expressão, de protagonismo, afirmação e projeção de si no mundo. Uma das finalidades das redes sociais é a de produzir nichos coletivos desterritorializados e de promover a fusão en- 
tre o virtual e o real sob a profusão de novas sociabilidades e dispositivos de modelagem da nossa subjetividade.

O Facebook é um território virtual de relacionamentos fundado em 2004 pelo norte-americano Mark Zuckerberg. Inicialmente, o projeto de Zuckberg era a de uma rede focada apenas em estudantes, entretanto, em setembro de 2006, o cadastro foi liberado para qualquer cibernauta e, desde então, o crescimento tem sido explosivo.

As redes sociais são territórios virtuais equipadas por pontos de subjetivação - ou pontos de conexão. O ciberespaço possui uma natureza híbrida e altamente dinâmica, onde múltiplas tribos se encontram e se tele-interagem. No Facebook, cada cibernauta possui sua própria virtualidade registrada a partir de uma conta, passando a se expressar combinando concretamente diversos tipos de agenciamentos que lhe atribuem sentido.

A produção coletiva no ciberespaço se dá no dizer do que está fazendo a cada momento, o verbo estar transborda o ser. A formulação "o que estou fazendo agora" dá pistas de quem sou eu. O modo de existir singularmente no virtual é atravessado pelo estar visível ao outro (DIAS \& COUTO, 2011).

Nas redes sociais, os sujeitos são confrontados pelos mais diversos tipos de agenciamento: agenciamentos reacionários, neoconservadores, revolucionários, reformistas e transgressores. Além disso, atuam também como meios para a produção estética e de autoafirmação.

Também promovem uma difusão contínua de afetos a partir de uma nova circulação de saberes e discursos. Nestes espaços, temos uma proliferação de enunciados que se transconectam e produzem uma consistência coletiva comunitária, desenvolve-se um novo significado e novas alternativas para a autoprodução.

As redes sociais constituem novos meios de sociabilidade para as minorias e grupos oprimidos, podendo encontrar nestes espaços, meios de luta e de agrupamento pelo afeto. Os homossexuais encontram nas redes sociais novos meios de sociabilidade, de agrupamento e de troca, assim como podem se expressar de uma forma mais espontânea em função de um distanciamento dos limites impostos pela heteronormatividade promovidos pelas redes sociais. 
No contexto das produções de experiências homossexuais nas redes sociais, constata-se que essas redes se têm constituído como importantes territórios alternativos para novas afetividades e mapas políticos de atuação social, assim como podem ser apropriados como armários tecnodigitais para aqueles que buscam por amores ocultos e vivências afetivas em segredo. Tudo vai depender da atuação molecular de cada sujeito social - de sua constituição política e de seus agenciamentos coletivos.

O armário é uma tecnologia de simulação e de regulação da produção desejante de homossexuais. De acordo com Miskolci (2012), podemos dizer que há uma persistência do armário na era das novas tecnologias. Com o advento da cibercultura, houve um aumento de diversas plataformas on-line segmentadas para um público LGBT como sites de anúncios, redes sociais e salas de bate-papo. A interatividade se impôs como mais relevância para pesquisas sobre a busca de parceiros afetivos e sexuais. Há uma marcante presença de homens que não possui sociabilidade gay na vida cotidiana da materialidade preexistente, mas que em navegação nos territórios virtuais assumem uma identidade homossexual sob a regulação do segredo que o armário tecnodigital permite.

Miskolci (2012) constata que os homens que vivem sob a regulação do armário sofrem e se sentem solitários, mas não são simples vítimas de uma simulação heteronormativa, pois detêm conexão afetiva. O sofrimento os alivia ou os "desculpabiliza" por agirem em desacordo com valores familiares, e a solidão também precisa ser compreendida como constitutiva de uma masculinidade hegemônica que recusa negociar seus desejos ou afetividades com outras pessoas.

A escolha do Facebook como território investigativo decorreu do fato desta plataforma multimídia ter se tornado um fenômeno global, colonizando o quotidiano da população e se tornando uma terra fértil a ser explorada. Hoje, é a rede social mais utilizada e oferece um campo de multiplicidade aos cibernautas: é um território virtual que permite uma pluralidade de dispositivos de simulação existencial.

O espaço analisado para a coleta de dados e discursos foi um grupo fechado de homossexuais e que contava no ano em que a pesquisa foi realizada com mais de sete mil membros, possui uma natureza híbrida 
com uma variedade de postagens e com uma diversidade de temas. $\mathrm{O}$ grupo se constitui como uma agência de afetos e enunciações, podendo ser apropriado como um espaço político para a subversão das forças de captura da heteronormatividade, bem como pode ser utilizado como um armário tecnodigital para aqueles que buscam vivências ocultas. O grupo conecta todos a um prisma, a singularidade do desejo homossexual e introduz os membros em múltiplos estratos de produção existencial e contato com forças que divergem em intencionalidade.

\section{A produção de experiências homossexuais na contempo- raneidade}

A etnografia virtual no maior grupo de sociabilidade de homossexuais brasileiros no Facebook foi feita a partir de uma sistematização de práticas discursivas e produção de sentidos. Tecnologia metodológica que subsidiou a interpretação dos atuais processos de produção existencial que maquinam as experiências homossexuais na contemporaneidade.

O grupo surgiu no ano 2011 e logo de início atraiu mais de três mil membros e no ano em que a pesquisa foi realizada contava com mais de 7.000 membros. O grupo é composto por indivíduos que buscam por compartilhamento de ideias, união, divertimento, agenda cultural e espaço político para a voz. É um espaço virtual que preza pelo respeito e uma boa interação entre seus os membros.

A entrada no grupo é livre. Caso o cibernauta queira, ele pode vir a se identificar em uma postagem de apresentação fixada pelos moderadores do grupo. Os membros podem vir a se interagir com perfis "reais" ou fictícios, não há normas enquanto a isso. Só não é permitido a entrada de mulheres e homens heterossexuais.

A sistematização das práticas discursivas coletadas no grupo foi feita através da produção de mapas, unidades de construção que demarcam os campos de possibilidades, atuação e produção das identidades homossexuais.

Através da análise materialista do espaço, contata-se que o espaço geográfico no qual estes jovens estão inseridos, foi estruturado sob um 
regime regulador heteronormativo, que marginaliza os indivíduos que não estão de acordo com a norma imposta, com o arranjo normativo codificado como sistema natural de ser. Em função das atuais mutações tecnoculturais, têm-se possibilitado novos conjuntos de ação e resistência aos homossexuais, que podem se agrupar pelo afeto e promover novos catastrofismos aos conjuntos normativos, reacionários e universais do Império Patriarcal-Heterocapitalista.

Conforme Miskolci [2012], os territórios on-line se estendem e se aproximam da maioria que vive na periferia, em cidades médias, pequenas ou mesmo na zona rural. Além disso, para pessoas que jamais quiseram [ou puderam] se expor de forma a frequentar algum nicho claramente gay, a rede virtual criou a possibilidade de criarem novas redes de inter-relações.

Os homossexuais, por estarem introduzidos em um núcleo territorial neoconservador, encontraram no ambiente simulado da web uma forma de conhecer parceiros e até fazer amizades sem a necessidade de uma evidente exposição de seus desejos num espaço público da materialidade preexistente, e que através de suas ações e agenciamentos coletivos nos espaços virtuais, podem interagir com forças que os fazem divergir do estado majoritário da heteronormatividade.

A intersubjetividade de homossexuais na contemporaneidade partilha de diferentes construções identitárias, híbridas e plurais, em interconexão com o território no qual a prática ocorre. Estas construções são evidenciadas através das enunciações discursivas e dos ciberagenciamentos tecidos em rede.

Conforme Moita Lopes (2003, p. 20):

O sujeito usa a linguagem a partir de suas marcas sócio-históricas ainda que certos traços identitários sejam suspensos em algumas práticas discursivas ou em alguns posicionamentos interacionais em uma mesma prática discursiva ou que possam se tornar mais relevantes em algumas práticas ou em certos posicionamentos interacionais.

Nesse sentido: 
Os conceitos de identidade e self tendem a ser associados com o foco interacional, no qual as pessoas constroem sua própria identidade individual ou coletiva no discurso. $\mathrm{O}$ pano de fundo para essa perspectiva são as identidades inquietantes no fluxo da modernidade tardia - a luta para encontrar identidades é um dos temas mais difundidos da modernidade tardia e um dos focos mais nítidos das reflexões da modernidade tardia (CHOULIARAKI; FAIRCLOUGH, 1999, p. 96).

As unidades de produção das experiências homossexuais perpassam por espaços sociais da materialidade preexistente: a família, a escola, a universidade, o mercado, e pelos territórios desterritorializados do ciberespaço: as redes sociais, os sítios eletrônicos, entre outros espaços. Estas unidades de produção existencial não estão separadas entre si, mas interconectadas sob uma mesma textura social, de produção de experiências e novas práticas de simulação existencial.

A natureza híbrida do ciberespaço se processa por múltiplos dispositivos de simulação da nossa virtualidade. São territórios que agrupam pelo afeto, onde diferentes sujeitos e grupos sociais se misturam e se teleinteragem sob um mesmo ciberorganismo. Os homossexuais encontram no Facebook uma terra fértil e híbrida para a diferença, como também, podem lidar com discursos de preconceitos e estereótipos, geralmente vinculados aos simulacros da masculinidade hegemônica do núcleo territorial hegemônico. Para alguns, a maquinaria do ciberespaço pode se constituir como uma espécie de armário tecnodigital em decorrência de sua desterritorialização. Cabem aos homossexuais, através de suas ações moleculares, se constituírem como uma força de transgressão diante das forças de captura que lhes fixam na norma e nos simulacros do heterocapitalismo.

Conforme Miskolci [2012], as tecnologias digitais trouxeram algumas novidades na afetividade e na esfera amorosa, como a possibilidade de visualizar, pela primeira vez, o universo de parceiros em potencial, ampliá-los numericamente e, sobretudo, a possibilidade de escolher como nunca antes. Dependendo da rede, podemos ter acesso há um mosaico descritivo de escolha. Passando por descrições numéricas, fotos ou 
ainda, por formulários e mecanismos de busca que permitem escolher quase tudo do possível parceiro: idade, altura, peso, cor de pele, cabelos, olhos e até mesmo tamanho do órgão genital.

Muitos homossexuais que buscam parceiros sexuais ou afetivos na web, usam como critério de seleção a "fita métrica", um simulacro reacionário que tem se tornado um filtro de seleção difundido nas relações on-line entre os homossexuais no núcleo hegemônico. De acordo com Miskolci [2012], os perfis de busca de parceiros com frases como: "não respondo a ninguém com menos de $1,80 \mathrm{~m}$ ", "nem entre em contato se não for malhado" ou "ignoro mensagens de caras com mais de 25 anos" deixam claro que as interações online, ao menos entre esses homens, tendem a ser muito mais regidas por padrões corporais de uma masculinidade hegemônica.

Em âmbito geral, percebe-se uma autoconsciência política crítica por parte dos cibernautas ativos na aldeia analisada. É importante para o homossexual ter a tomada de autoconsciência de que o território que se vive é revestido por forças de captura de inserção a um regime heteronormativo. A autoconsciência torna o indivíduo mais ativo na luta, estando sempre à borda da emancipação política e de seu estado majoritário.

Em geral, nota-se também pelas postagens do grupo uma grande quantidade de discursos de discriminação, preconceitos e afirmação de estereótipos àqueles que escapam as tecnologias de simulação da masculinidade hegemônica - uma estrutura simbólica violenta de inserção dos indivíduos a quadros de padronização do desejo a modelos majoritários da heteronormatividade.

Você pode simular uma identidade homossexual, mas desde que esteja codificado na norma do homem branco, musculoso, macho, rico e bem-dotado. Se você não se enquadra a este regime regulamentador, você está à margem do núcleo hegemônico homossexual.

O núcleo hegemônico homossexual é um polo reacionário de produção existencial que tem como força de captura, as ficções culturais das masculinidades hegemônicas, que tem como modelo de simulação, o homem viril, ativo, bem-dotado e não-afeminado da heteronormatividade. É um modelo violento, que gera angústia entre os homossexuais que 
se esforçam para se enquadrarem a este modelo e também, discriminação àqueles que estão engajados em outras performatividades de gênero.

A cultura do núcleo hegemônico homossexual é baseada no regime de signos de heteronormatividade, mantida por uma pluralidade de estereótipos entre os próprios membros da tribo, constituindo-se como impulsor para preconceitos e homofobia entre os próprios homossexuais. Como um espelho da heterossexualidade, a homossexualidade hegemônica é codificada na norma falocêntrica, em um núcleo normalizador que marginaliza, inclusive, aqueles que estão engajados em seu devirrevolucionário ou em performatividades transgressoras de gênero.

O desejo pela masculinidade hegemônica faz com que os homossexuais simulem uma masculinidade padrão, fixada na imagem de um homem cristalizado na ordem fálica da heteronormatividade. Apesar de simularem uma identidade homossexual, muitos acabam se moldando aos valores e as tecnologias de simulação de uma masculinidade hegemônica que vem a subalternizar os homossexuais do núcleo transgressor que simulam uma política emancipatória dos sistemas de programação da heteronormatividade. Os que se inserem no regime hegemônico, estão a simular o jogo do opressor, legitimando a sua ficção política.

A produção das experiências homossexuais na contemporaneidade ainda perpassa rigidamente pelas ficções políticas da heteronormatividade, em um atravessamento de masculinidades majoritárias e masculinidades minoritárias. São poucos os que estão a romper com os códigos das masculinidades que se aproxima dos modelos cristalizados em nosso dia a dia como padrões.

A fluidez das identidades sociais tem fabricado novos mapas políticos e experiências sociais que confrontam os homens a repensarem seus padrões e comportamentos reacionários. Em território brasileiro, em decorrência da modernidade tardia, os valores ainda estão bastante petrificados na moralidade heteronormativa, patriarcal e cristã, que acabam por regular o comportamento e a produção desejante dos indivíduos. A sociedade brasileira ainda possui um núcleo de subjetivação bastante conservador baseado na insistência em não reconhecer outros tipos de simulações sexuais e performatividades de gênero. 
Grande parte das simulações da homossexualidade são transposições de modelos endurecidos no sistema de programação da heterossexualidade compulsória. A produção da homossexualidade na contemporaneidade ainda se encontra bastante enraizada nos sistemas simbólicos da heteronormatividade, nesse sentido, ela acaba mantendo os mesmos códigos da heteronormatividade, o mesmo registro simbólico.

O grupo analisado também se apresenta também como uma espécie de armário tecnodigital. O simulacro do armário passou a habitar os espaços virtuais. Ao mesmo tempo em que o Facebook dá uma maior liberdade de expressão por estar desterritorializado, ele se constitui também como um armário para os "enrustidos", que passam a usufruir dos novos espaços cibernéticos para buscar encontros às escondidas.

Para Sedwick (2007), mesmo a nível molecular, até entre as pessoas mais assumidamente gays há pouquíssimas que não estejam no armário com alguém que seja pessoal, econômica ou institucionalmente importante para elas. Além disso, a elasticidade mortífera da presunção heterossexista. O armário foi a estrutura definidora da opressão gay no século XX e continua a ser bastante difundida, sobretudo com a proliferação dos espaços virtuais.

A influência e a pressão do regime regulador da heteronormatividade é tão forte que até mesmo quem está inserido na construção de uma performance minoritária acaba sendo capturado por algum código ou padrão da rede de poder da heteronormatividade.

O grupo é também um espaço que pode ser palco para a diferença, e que através da experiência e da sociabilidade entre os cibernautas da aldeia, o desejo pode vir a tomar novas pulsações, o fazendo divergir de seu estado hegemônico. Além de reconstruírem suas virtualidades nos encontros com o outro, os homossexuais podem edificar agenciamentos coletivos para movimentos de transgressão aos poderes hegemônicos. $\mathrm{O}$ Facebook pode muito bem vir a se constituir como um mecanismo estratégico, um agenciador de forças de transgressão. A aldeia do Facebook reflete bem o palco das lutas sociais na contemporaneidade, sendo assim, a atuação política nas redes sociais pode indicar caminhos, eixos e orientações que podem golpear as formações reacionárias e neoconservadoras da cultura totalitária. 
A atuação política no grupo analisado é segmentada por forças que diferem entre si. Tem aqueles que estão conscientes da sua dominação e se constituem como uma força política transgressora e progressista. Como também tem aqueles que ainda caminham nas fronteiras do neoconservadorismo e dos sistemas de captura do desejo das forças hegemônicas.

Os homossexuais podem se apropriar destes novos espaços de subjetivação que as máquinas propõem como focos mutantes de reinvenção e da diferença. O caráter híbrido e plural da contemporaneidade tem nos colocado nas fronteiras com novas experiências.

No Brasil, os principais espaços socializadores - a família, as escolas e a mídia dominante - são dirigidos por uma moralidade violenta patriarcal, cristã e altamente heteronormativa. São instituições que mantêm em circulação as tecnologias discursivas de gênero, que são verdadeiras maquinarias de normatização e programação dos corpos ao regime simbólico da heteronormatividade. A família nuclear patriarcal ainda é um modelo bastante difundido no Brasil, e tem sido bastante utilizada como estratégia política para as frentes neoconservadoras.

\section{Considerações finais}

A produção das identidades homossexuais em tempos de fluidez perpassa por diferentes espaços de sociabilidade que orientam e moldam o comportamento [mas não determina] e por uma paisagem existencial móvel de descobertas e experiências. A interconexão entre espaços sociais e espaços virtuais, pluga a subjetividade em um movimento de reconstrução contínua, a ser interpretada e simulada sob diferentes maneiras.

A produção da identidade homossexual na contemporaneidade é marcada por uma sucessão de experiências [afetivas e sexuais] e que são as responsáveis pela formação da maturidade, da identidade e enfrentamento das inquietações existenciais que afetam grande parte dos homossexuais. Como hipótese, podemos descrever a formação da identidade homossexual a partir de três estágios. São fases não lineares que se intercalam no processo de fragmentação da identidade: 
Denomino o primeiro estágio de QUEM SOU EU?: É a fase dos primeiros questionamentos existenciais, marcada por muita confusão e desconhecimento, uma vez que o indivíduo ainda está adaptado ao regime regulamentador da heterossexualidade, acreditando que a identidade heterossexual é uma estrutura intrínseca a sua constituição. O "posso ser homossexual?" passa a ser um pensamento inquietante. Nosso inconsciente passa a ser habitado por um duelo de forças: forças internas do desejo e forças de fora [medo e pressão social - duas forças de captura da heteronormatividade]. $\mathrm{O}$ indivíduo passa a se confrontar internamente com este atravessamento caótico: onde as forças de captura se confrontam com as pulsões desejantes e fantasias.

O segundo estágio denomino de MUTAÇÃO EXISTENCIAL: Fase da bifurcação. É uma fase difícil, de muitos questionamentos com relação à identidade e a sexualidade. É a fase armário e das novas pulsões desejantes. O que vai desdobrar o desejo deste estágio será a sucessão de acontecimentos e experiências.

A princípio, muitos buscam vivências ocultas e em segredo, levando os indivíduos a viverem sob a regulação do armário. Nessa fase, os homossexuais que não lidam bem com a sua identidade "marginal", buscam o armário como uma ferramenta de busca para parceiros sexuais como uma forma de amenizar a dor da repressão, mas que depois do ato, voltam a simular sua heterossexualidade e com sentimentos de culpa e desprezo pela identidade homossexual.

Se o indivíduo não tiver boas expectativas quanto a sua descoberta, ele pode conviver com a repressão do desejo e seus efeitos, tais como, a melancolia, a agressividade e a depressão. É um estágio marcado por sentimentos de aceitação concomitantes a sentimentos de vazio e negação, sentimentos que mudam de acordo com o impacto da homossexualidade para o indivíduo e o seu nível de enfrentamento.

O terceiro e último estágio é o da PRODUÇÃO DESEJANTE: É a fase de aceitação e de afirmação. Neste estágio, os indivíduos que antes temiam a socialização com pessoas da mesma tribo com medo da marginalização, passam a produzir experiências compartilhadas entre membros da mesma tribo. É a fase que parte dos homossexuais buscam enfrentar a saída do armário e a desconstruir o sistema de programação 
dominante da heteronormatividade. Fase das primeiras aventuras afetivoamorosas. Inclusive, muitos homossexuais enrustidos acabam enfrentando o armário e a heteronormatividade com o aporte do amor e da afetividade. É o momento de novo compromisso ético-político onde o indivíduo incorpora a homossexualidade como uma nova identidade a sua subjetividade, propiciando a autoaceitação e afirmação política de sua identidade minoritária.

A partir da análise das práticas discursivas e da minha vivência no grupo analisada, constata-se que este o grupo se constitui como uma porta de entrada ao universo da cultura homossexual. É um território onde você pode conhecer as práticas, costumes e hábitos que maquinam a cultura homossexual na contemporaneidade. É também um espaço político e de intervenção no outro e pelo outro, podendo administrar novos sentidos e a quebrar estereótipos. É um também um território existencial, de vivência de novas afetividades. O sistema de em rede possibilita uma variedade de usos dos afetos e conexões, tudo vai depender das orientações do desejo e da forma como cada indivíduo se constitui naquele espaço.

Os espaços virtuais se apresentam como núcleos de subjetivação diferenciados dos núcleos de sociabilidade da materialidade preexistente. As redes sociais trouxeram novos redimensionamentos para a subjetividade e produção das identidades por se constituírem como práticas sociais construídas a partir da interconectividade e não localidade. Há no ciberespaço, um novo processamento de novas tecnologias de simulação e sistemas de informações, permitindo a produção de novos sentidos, afetividades e experiências sociais.

\section{Referências}

CHOULIARAKI, Lilie.; FAIRCLOUGH, Norman. Discourse in late modernity: Rethinking Critical Discourse Analysis. Edinburg: Edinburg University Press, 1999.

COLPANI, Felipe. Corpus, Máquinas \& Afetos. As experiências homossexuais na contemporaneidade. 2015. 240f. Dissertaç̧ão (Mestrado 
em Educação) - Programa de Pós Graduação em Educação, Centro de Ciências Humanas e Biológicas, Universidade Federal de São Carlos/SP, 2015.

DIAS, Cristiane.; COUTO, Olivia F. As redes sociais na divulgação e formação do sujeito do conhecimento: compartilhamento e produção através da circulação de Ideias. Linguagem em [Dis]curso, v. 11, n. 3, p. 631-648, 2011.

MISKOLCI, Richard. A Gramática do Armário: notas sobre segredos e mentiras em relações homoeróticas masculinas mediadas digitalmente. In: PELÚCIO, L.; SOUZA, L. A.; SABATINE, T. e MAGALHÃES, B. Sexualidade, Gênero e Mídia - Olhares Plurais para o Cotidiano. Marília: Cultura Acadêmica, 2012.

MOITA LOPES, Luiz P. Socioconstrucionismo: discurso e identidades sociais. In: MOITA LOPES, L. P. Discursos de Identidades. Campinas: Mercado de Letras, 2003.

SPINK, Mary J. [org.]. Práticas discursivas e produção de sentidos no cotidiano: aproximações teóricas e metodológicas. São Paulo: Cortez, 1999.

SEDGWICK, Eve K. A epistemologia do armário. Cadernos Pagu, n.28, jan./jun. 2000, p. 19-54 